\title{
IPTEKS PENCATATAN DAN PERHITUNGAN PAJAK PENGHASILAN (PPh 21) PADA PT.BANK RAKYAT INDONESIA (PERSERO) Tbk. CABANG MANADO UNIT MALALAYANG
}

\author{
Vernando Viki Tambingon \\ Jurusan Akuntansi, Fakultas Ekonomi dan Bisnis, Universitas Sam Ratulangi, Jl. Kampus Bahu, Manado, \\ 95115, Indonesia \\ E-mail : viki.tambingon@gmail.com
}

\begin{abstract}
Most of the income state normally came from tax and in that case then state should establish its regulations to control the tax. One regulation is income tax article 21 which is tax for individual income. PT. Bank Rakyat Indonesia is one of banks owned by state or government and established for long age. As PT. Bank Rakyat Indonesia have large business then its employees have taxed with income tax article 21. Till recent, the income tax article 21 for employess is applied correctly and follow the rule of income tax regulations.
\end{abstract}

Keywords : recording, reporting, income tax, bank

\section{PENDAHULUAN}

Pajak Penghasilan 21 atau PPh 21 adalah Pajak atas penghasilan berupa gaji, upah, honorarium, tunjangan, dan pembayaran lain dengan nama dan dalam bentuk apapun sehubungan dengan pekerjaan atau jabatan, jasa,dan kegiatan yang dilakukan oleh orang pribadi Subjek Pajak dalam negeri, sebagaimana dimaksud dalam Pasal 21 Undang Undang No.36 Tahun 2008 tentang Pajak Penghasilan.Apabila orang pribadi Subjek Pajak dalam negeri memperoleh penghasilan dan dikenakan $\mathrm{PPh}$ Pasal 21, maka menjadi wajib pajak orang pribadi dalam negeri. Warga Negara asing (orang asing) yang tinggal atau berniat tinggal di Indonesia lebih dari 183 hari dalam satu tahun termasuk dalam pengertian wajib pajak orang pribadi dalam negeri, sehingga atas penghasilan orang asing tersebut apabila lebih dari 183 hari tinggal di Indonesia merupakan objek PPh Pasal 21. Masa Desember atau masa pajak tertentu di mana pegawai tetap berhenti bekerja.Dalam Masa Pajak Desember $\mathrm{PPh}$ Pasal 21 dihitung dari Januari atau pegawai mulai bekerja sampai dengan Desember.Dalam Masa Pajak Tertentu (bagi pegawai tetap berhenti bekerja) PPh Pasal 21 dihitung dari Januari atau pegawai mulai bekerja sampai dengan Masa Pajak pegawai tetap berhenti bekerja. Pemotong PPh Pasal 21 adalah Wajib Pajak orang pribadi atau Wajib Pajak badan, termasuk bentuk usaha tetap, yang mempunyai kewajiban untuk melakukan pemotongan pajak atas Penghasilan Sehubungan dengan Pekerjaan, Jasa, dan Kegiatan Orang Pribadi sebagaimana dimaksud dalam Pasal 21 Undang-Undang No.36 Tahun 2008 tentang Pajak Penghasilan.

Sebagian besar penerimaan Negara adalah dari sektor pajak. Hal tersebut dikarenakan sampai detik ini penerimaan Negara dari sektor pajak masih menjadi prioritas utama untuk mensukseskan dan melancarkan pembangunan nasional yang terus berkesinambungan. Bagi Negara pajak merupakan salah satu sumber penerimaan terpenting yang akan digunakan untuk membiayai pengeluaran Negara baik pengeluaran rutin maupun pengeluaran untuk pembangunan. Pada dasarnya setiap orang tidak suka membayar pajak dan berusaha untuk membayar pajak sekecil mungkin karena dengan membayar pajak berarti mengurangi kemampuan ekonomis mereka,segala upaya untuk penghematan pajak dalam perusahaan pun dilakukan dengan memanfaatkan celah-celah peraturan perpajakan yang ada dengan harapan memperolah laba bersih setelah pajak.Salah satunya melakukan penghematan PPh badan 
yang dapat dilakukan pada biaya-biaya yang berkaitan dengan kesejahteraan karyawan.Diantaranya adalah pada $\mathrm{PPh}$ Pasal 21 atas penghasilan yang diterima oleh karyawan. Ada 3 (tiga) metode yang dapat dipilih oleh perusahaan dalam menerapkan pemungutan PPh Pasal 21 karyawan yaitu :

1. Metode pertama, besarnya PPh Pasal 21 dapat dipotong langsung dari gaji yang diterima oleh karyawan.

2. Metode kedua yang dapat diterapkan adalah dengan memberikan tunjangan tambahan yang berupa Tunjangan Pajak. Tunjangan Pajak yang diberikan akan menambah Penghasilan Kena Pajak (PKP) karyawan,sehingga PPh Pasal 21 menjadi lebih besar.

3. Metode yang ketiga adalah dengan memberikan tambahan pada penghasilan bruto karyawan sebesar pajak yang harus ditanggung karyawan.Metode ini sering dikenal dengan sebutan metode Gross Up.

Pajak Penghasilan Pasal 21 merupakan salah satu pajak langsung yang di pungut pemerintah pusat atau merupakan pajak Negara yang berasal dari pendapatan rakyat.Dari berbagai jenis pajak yang ada, Pajak Penghasilan Pasal 21 merupakan salah satu pajak yang memberikan masukan sangat besar bagi Negara. Kebijakan pemerintah dalam mengatur Pajak Penghasilan (PPh) Pasal 21 antara lain dengan dikeluarkannya undangundang nomor 7 tahun 1983 sebagaimana telah diubah dengan undangundang nomor 10 tahun 1994, dan perubahan terakhir dengan undangundang nomor 17 tahun 2008. Selanjutnya aturan pelaksanaannya adalah dengan dikeluarkannya keputusan Direktorat Jendral Pajak No.KEP545/PJ/2008 tentang petunjuk pelaksanaan pemotongan, penyetoran dan pelaporan $\mathrm{PPh}$ Pasal 21 sehubungan dengan pekerjaan jasa dan kegiatan orang pribadi. Walaupun pajak berpengaruh terhadap aspek kehidupan usaha dan keputusan bisnis,tidaklah berarti bahwa pajak tersebut tidak dapat dikendalikan. Dengan memahami secara benar segala ketentuan peraturan perundang-undangan terus menerus perubahannya,sesungguhnya pajak tersebut dapat dikelola dengan baik agar tercapai efisiensi pembayaran pajak,karena suatu pengelolaan pajak yang efektif merupakan hal yang vital bagi suatu usaha yang berorientasi kepada keuntungan.

Pengelolaan kewajiban pajak tersebut sering disosialisasikan dengan suatu elemen dalam suatu perusahaan yang disebut Tax Management (manajemen pajak). Langkah awal dalam manajemen pajak adalah perencanaan pajak (Tax planning) yakni mengumpulkan dan melakukan penelitian terhadap peraturan perpajakan agar dapat diselidiki jenis tindakan penghematan pajak yang dapat dilakukan dan masih tetap berada dalam bingkaian ketentuan perpajakan.Perubahan undang-undang pajak yang dilakukan oleh pemerintah dimaksudkan untuk menyempurnakan system perpajakan yang telah ada, adapun undangundang perpajakan yang baru tersebut mulai berlaku tahun 2008. Wajib pajak yang diperlakukan sebagai subyek dalam system pemungutan pajak khususnya pada bidang pajak penghasilan (PPh) disebabkan wajib pajak diberikan kepercayaan penuh oleh negara (direktorat jendral pajak) untuk menghitung, memperhitungkan, menbayar dan melaporkan sendiri jumlah pajak yang terhutang sesuai dengan Self Assetment. Self Assetment adalah keputusan wajib pajak dalam melaksanakan peraturan perundang-undangan perpajakan Indonesia yang berlaku tersebut.

Dengan sistem pemungutan pajak yang baru atau sering disebut dengan sistem full self assesment, dimana wajib pajak merupakan subyek pajak yang diberikan kepercayaan penuh untuk menghitung dan melaksanakan sendiri kewajiban perpajakannya. Tax planning adalah suatu metode yang dapat dilakukan oleh wajib pajak untuk memaksimalkan penghasilan setelah pajak dengan cara merekayasa agar beban pajak dapat ditekan serendah mungkin dengan memanfaatkan peraturan yang ada dalam undang-undang. 


\section{TINJAUAN PUSTAKA}

\subsection{Pengertian bank, jenis-jenis bank, fungsi bank}

Berdasarkan Undang-Undang No. 10 tahun 1998, bank merupakan lembaga keuangan yang memberikan jasa keuangan yang paling lengkap, disamping menyalurkan dana atau memberikan pinjaman (kredit) juga melakukan usaha menghimpun dana dari masyarakat luas dalam bentuk simpanan, serta memberikan jasa-jasa keuangan lainnya yang mendukung dan memperlancar kegiatan memberi pinjaman dengan kegiatan menghimpun dana.

Berdasarkan Undang-Undang No. 10 tahun 1998, maka jenis-jenis bank menurut fungsinya adalah :

1. Bank Sentral, yaitu bank yang tugasnya dalam menerbitkan uang kertas dan logam sebagai alat pembayaran yang sah dalam suatu negara dan mempertahankan konversi uang dimaksud terhadap emas atau perak atau keduanya.

2. Bank Umum, yaitu bank yang bukan saja dapat meminjamkan atau menginvestasikan berbagai jenis tabungan yang diperolehnya, tetapi juga dapat memberikan pinjaman dari menciptakan sendiri uang giral.

3. Bank Perkreditan Rakyat (BPR), yaitu bank yang melaksanakan kegiatan usaha secara konvensional atau berdasarkan prinsip syariah yang dalam kegiatannya tidak memberikan jasa dalam lalu lintas pembayaran.

Sedangkan fungsi bank adalah :

1. Penghimpun dana untuk menjalankan fungsinya sebagai penghimpun dana maka bank memiliki beberapa sumber yang secara garis besar ada tiga sumber, yaitu: (a) dana yang bersumber dari bank sendiri yang berupa setoran modal waktu pendirian; (b) dana yang berasal dari masyarakat luas yang dikumpulkan melalui usaha perbankan seperti usaha simpanan giro, deposito dan tabanas; dan (c) dana yang bersumber dari Lembaga Keuangan yang diperoleh dari pinjaman dana yang berupa Kredit Likuiditas dan Call Money (dana yang sewaktu-waktu dapat ditarik oleh bank yang meminjam) dan memenuhi persyaratan.

2. Penyalur dana-dana yang terkumpul oleh bank disalurkan kepada masyarakat dalam bentuk pemberian kredit, pembelian surat-surat berharga, penyertaan, pemilikan harta tetap.

3. Pelayan Jasa Bank dalam mengemban tugas sebagai "pelayan lalu-lintas pembayaran uang" melakukan berbagai aktivitas kegiatan antara lain pengiriman uang, inkaso, cek wisata, kartu kredit dan pelayanan lainnya.

\subsection{Konsep Perpajakan}

Mardiasmo (2011) pajak adalah iuran rakyat kepada kas negara berdasarkan undangundang (yang dapat dipaksakan) dengan tidak mendapat jasa timbal balik (kontra prestasi), yang langsung dapat ditunjuk dan dapat digunakan untuk membayar pengeluaran umum. Menurut Pudyatmoko (2009), pajak adalah iuran wajib kepada negara (yang dapat dipaksakan) yang terutang oleh yang wajib membayarnya menurut peraturan-peraturan, dengan tidak mendapat prestasi kembali, yang langsung dapat ditunjuk, dan yang digunakan adalah untuk membiayai pengeluaran-pengeluaran umum yang berhubungan dengan tugas negara untuk menyelenggarakan pemerintahan.

\subsection{Pajak Penghasilan PPh Pasal 21}

Menurut Undang-Undang Nomor 36 Tahun 2008 dan Tansuria (2010), pajak penghasilan adalah pajak yang dikenakan atas penghasilan berupa gaji, upah, honorarium, tunjangan dan pembayaran lain yang diterima oleh Wajib Pajak Orang Pribadi dalam negeri sehubungan dengan pekerjaan, jasa dan kegiatan. Pajak Penghasilan merupakan pajak yang dibebankan pada penghasilan perorangan, perusahaan atau badan hukum lainnya. Pajak 
Penghasilan bias diberlakukan progresif, proporsional atau regresif. Objek Pajak PPh Pasal

21 yang dipotong adalah :

1. Penghasilan yang diterima atau diperoleh pegawai tetap, baik berupa penghasilan yang bersifat teratur maupun tidak teratur.

2. Penghasilan yang diterima atau dperoleh penerima pensiun secara teratur berupa uang pensiun atau pengasilan sejenisnya.

3. Penghasilan sehubungan dengan pemutusan hubungan kerja dan penghasilan sehubungan dengan pensiun yang diterima secara sekaligus berupa uang pesangon, uang manfaat pensiun, tunjangan hari tua atau jaminan hari tua dan pembayaran lain sejenis.

4. Penghasilan pegawai tidak tetap atau tenaga kerja lepas, berupa upah harian, upah mingguan, upah satuan, upah borongan atau upah yang dibayarkan secara bulanan.

5. Imbalan kepada bukan pegawai, antara lain berupa honorarium, komisi, fee dan imbalan sehubungan dengan pekerjan, jasa dan kegiatan yang dilakukan.

6. Imbalan kepada peserta kegiatan, antara lain berupa uang saku, uang representasi, uang rapat, honorarium, hadiah atau penghargaan dengan nama dan dalam bentuk apapun dan imbalan sejenis dengan nama apapun.

7. Penerimaan dalam bentuk natura dan/atau kenikmatan lainnya dengan nama dan dalam bentuk apapun yang diberikan oleh : (a) Bukan Wajib Pajak; (b) Wajib Pajak yang dikenakan Pajak Penghasilan yang bersifat final; atau (c) Wajib Pajak yang dikenakan Pajak Pengahasilan berdasarkan norma penghitungan khusus.

\section{METODE DAN TEKNIK PENERAPAN IPTEKS}

\subsection{Metode Penerapan Ipteks}

Dalam praktek perhitungan PPH 21 perusahaan menggunakan berbagai macam metode yaitu gross, net, gross-up, dan non gross-up.

1. Metode Gross. Contoh $\mathrm{PPh} 21$ terutang dibayar sendiri oleh karyawan yang bersangkutan :

Si A (TK/0)

Gaji sebulan = Rp. 5.000.000,-

$\mathrm{PPh} 21$ yang dibayar sendiri $=\mathrm{Rp} 30.000,-$

Take home pay $\quad=$ Rp.4.970.000,-

2. Metode Net. Contoh PPh 21 dibayar/ditanggung pemberi kerja :

Si A $(\mathrm{TK} / 0)$

Gaji sebulan

$$
=\text { Rp. 5.000.000,- }
$$

$\mathrm{PPh} 21$ yang dibayar pemberi kerja (kenikmatan dan bukan biaya bagi pemberi kerja)

$$
=\text { Rp. 30.000,- }
$$

Take home pay

$$
=\text { Rp. 5.000.000,- }
$$

3. Metode Gross-Up. Contoh karyawan diberikan tunjangan pajak (gajinya dinaikkan) sebesar pajak yang dipotong :

Si A (TK/0)

Gaji sebulan = Rp. 5.000.000,-

Tunjangan PPh (merupakan biaya bagi pemberi kerja sehingga bisa mengurangi pajak (deductable expense) $=$ Rp. 30.000

Jumlah Gaji = Rp. 5.030.000,-

Dipotong PPh $21=$ Rp. $30.000,-$

Take home pay $=\quad$ Rp. 5.000.000,- 


\subsection{Teknik Penerapan Ipteks}

Menurut Peraturan Direktur Jenderal Pajak Nomor PER-32/PJ/2015 tentang Pajak Penghasilan Pasal 21, pengertian dari PPh 21 adalah pajak atas penghasilan berupa gaji, upah, honorarium, tunjangan dan pembayaran lain dengan nama dan dalam bentuk apapun yang sehubungan dengan pekerjaan atau jabatan, jasa, dan kegiatan yang dilakukan oleh orang pribadi subyek pajak dalam negeri. Singkatnya, PPH 21 adalah pajak yang dikenakan untuk setiap penghasilan yang diperoleh subyek pajak. Subyek pajak disini adalah pihak yang memperoleh penghasilan. Maka dari itu, setiap karyawan, pegawai, atau pekerja yang memperoleh gaji wajib membayarkan pajak penghasilan (PPh 21). Perhitungan $\mathrm{PPh} 21$ sendiri menyesuaikan dengan Penghasilan Tidak Kena Pajak (PTKP) yang ditetapkan oleh Direktorat Jenderal Pajak yaitu:

\begin{tabular}{|c|c|c|}
\hline Status Kena Wajib Pajak & Jumlah Per Tahun (Rp.) & Jumlah Per Bulan (Rp.) \\
\hline Pribadi & 54.000.000,- & 4.500.000,- \\
\hline Kawin (Tanpa Tanggungan) & $4.500 .000,-$ & $375.000,-$ \\
\hline $\begin{array}{l}\text { Setiap Anggota Keluarga Sedarah } \\
\text { dan Dalam Garis Keturunan Lurus } \\
\text { (Tanggungan) } \\
3 \text { (tiga) orang }\end{array}$ & $4.500 .000,-$ & $375.000,-$ \\
\hline
\end{tabular}

\section{HASIL PENGABDIAN DAN PEMBAHASAN}

\subsection{Gambaran Objek Penerapan Ipteks}

Bank Rakyat Indonesia (BRI) adalah salah satu bank milik pemerintah yang terbesar di Indonesia. Pada awalnya Bank Rakyat Indonesia (BRI) didirikan di Purwokerto, Jawa Tengah oleh Raden Bei Aria Wirjaatmadja dengan nama De Poerwokertosche Hulp en Spaarbank der Inlandsche Hoofden atau "Bank Bantuan dan Simpanan Milik Kaum Priyayi Purwokerto", suatu lembaga keuangan yang melayani orang-orang berkebangsaan Indonesia (pribumi). Lembaga tersebut berdiri tanggal 16 Desember 1895, yang kemudian dijadikan sebagai hari kelahiran BRI. Pada periode setelah kemerdekaan RI, berdasarkan Peraturan Pemerintah No. 1 tahun 1946 Pasal 1 disebutkan bahwa BRI adalah sebagai Bank Pemerintah pertama di Republik Indonesia. Dalam masa perang mempertahankan kemerdekaan pada tahun 1948, kegiatan BRI sempat terhenti untuk sementara waktu dan baru mulai aktif kembali setelah perjanjian Renville pada tahun 1949 dengan berubah nama menjadi Bank Rakyat Indonesia Serikat. Pada waktu itu melalui PERPU No. 41 tahun 1960 dibentuklah Bank Koperasi Tani dan Nelayan (BKTN) yang merupakan peleburan dari BRI, Bank Tani Nelayan dan Nederlandsche Maatschappij (NHM). Kemudian berdasarkan Penetapan Presiden (Penpres) No. 9 tahun 1965, BKTN diintegrasikan ke dalam Bank Indonesia dengan nama Bank Indonesia Urusan Koperasi Tani dan Nelayan.

Setelah berjalan selama satu bulan, keluar Penpres No. 17 tahun 1965 tentang pembentukan bank tunggal dengan nama Bank Negara Indonesia. Dalam ketentuan baru itu, Bank Indonesia Urusan Koperasi, Tani dan Nelayan (eks BKTN) diintegrasikan dengan nama Bank Negara Indonesia unit II bidang Rural, sedangkan NHM menjadi Bank Negara Indonesia unit II bidang Ekspor Impor (Exim). Berdasarkan Undang-Undang No. 14 tahun 1967 tentang Undang-undang Pokok Perbankan dan Undang-undang No. 13 tahun 1968 tentang Undang-undang Bank Sentral, yang intinya mengembalikan fungsi Bank Indonesia sebagai Bank Sentral dan Bank Negara Indonesia Unit II Bidang Rular dan Ekspor Impor dipisahkan masing-masing menjadi dua Bank yaitu Bank Rakyat Indonesia dan Bank Ekspor Impor Indonesia. Selanjutnya berdasarkan Undang-undang No. 21 tahun 1968 menetapkan kembali tugas-tugas pokok BRI sebagai bank umum. 
Sejak 1 Agustus 1992 berdasarkan Undang-Undang Perbankan No. 7 tahun 1992 dan Peraturan Pemerintah RI No. 21 tahun 1992 status BRI berubah menjadi perseroan terbatas. Kepemilikan BRI saat itu masih 100\% di tangan Pemerintah Republik Indonesia. Pada tahun 2003, Pemerintah Indonesia memutuskan untuk menjual 30\% saham bank ini, sehingga menjadi perusahaan publik dengan nama resmi PT. Bank Rakyat Indonesia (Persero) Tbk., yang masih digunakan sampai dengan saat ini.

\subsection{Pembahasan}

Tarif Pajak Penghasilan (PPh) Pasal 21 Direktorat Jenderal Pajak telah menerbitkan Peraturan Direktorat Jenderal Pajak Nomor PER- 31/PJ/2009 tentang pedoman teknis tata cara pemotongan, penyetoran dan pelaporan Pajak Penghasilan Pasal 21 sehubungan dengan pekerjaan, jasa dan kegiatan orang pribadi. Peraturan tersebut merupakan petunjuk pelaksanaan dari Menteri Keuangan-252/PMK.03/2008, tentang petunjuk pemotongan atas penghasilan sehubungan dengan pekerjaan, jasa dan kegiatan orang pribadi. Untuk menghitung Pajak Penghasilan Pasal 21, terlebih dahulu diketahui dasar pengenaanpajaknya. Untuk Wajib Pajak dalam negeri dan Badan Usaha Tetap, yang menjadi dasar pengenaan pajaknya adalah Penghasilan Kena Pajak. Pajak penghasilan bagi Wajib Pajak dihitung dengan cara mengalikan Penghasilan Kena Pajak dengan tarif pajak sesuai dalam UndangUndang Pajak Penghasilan Pasal 17 didasarkan pada tarif Progresif, yaitu tarif yang didasarkan pada lapisan Penghasilan Kena Pajak, yang artinya persentase tarif yang digunakan semakin besar jika jumlah yang dikenakan pajak semakin besar. Adapun tarif Pasal 17 Undang-Undang Pajak Penghasilan, yaitu :

\begin{tabular}{llr}
\hline \multicolumn{1}{c}{ Lapisan } & \multicolumn{1}{c}{ Penghasilan Kena Pajak } & Tarif \\
\hline I & s.d Rp 50.000.000 & $5 \%$ \\
II & Di atas Rp 50.000.000 s.d Rp 250.000.000 & $15 \%$ \\
III & Di atas Rp 250.000.000 s.d Rp 500.000.000 & $25 \%$ \\
IV & Di atas Rp 500.000.000 & $30 \%$ \\
\hline
\end{tabular}

Pegawai Pegawai A jenis kelamin laki-laki dengan status $\mathrm{K} / 2$ memiliki penghasilan bruto perbulan sebesar Rp.10.000.000 dan menjadi Rp. 120.000.000 apabila disetahunkan, sehingga PPh 21 dapat dihitung sebagai berikut :

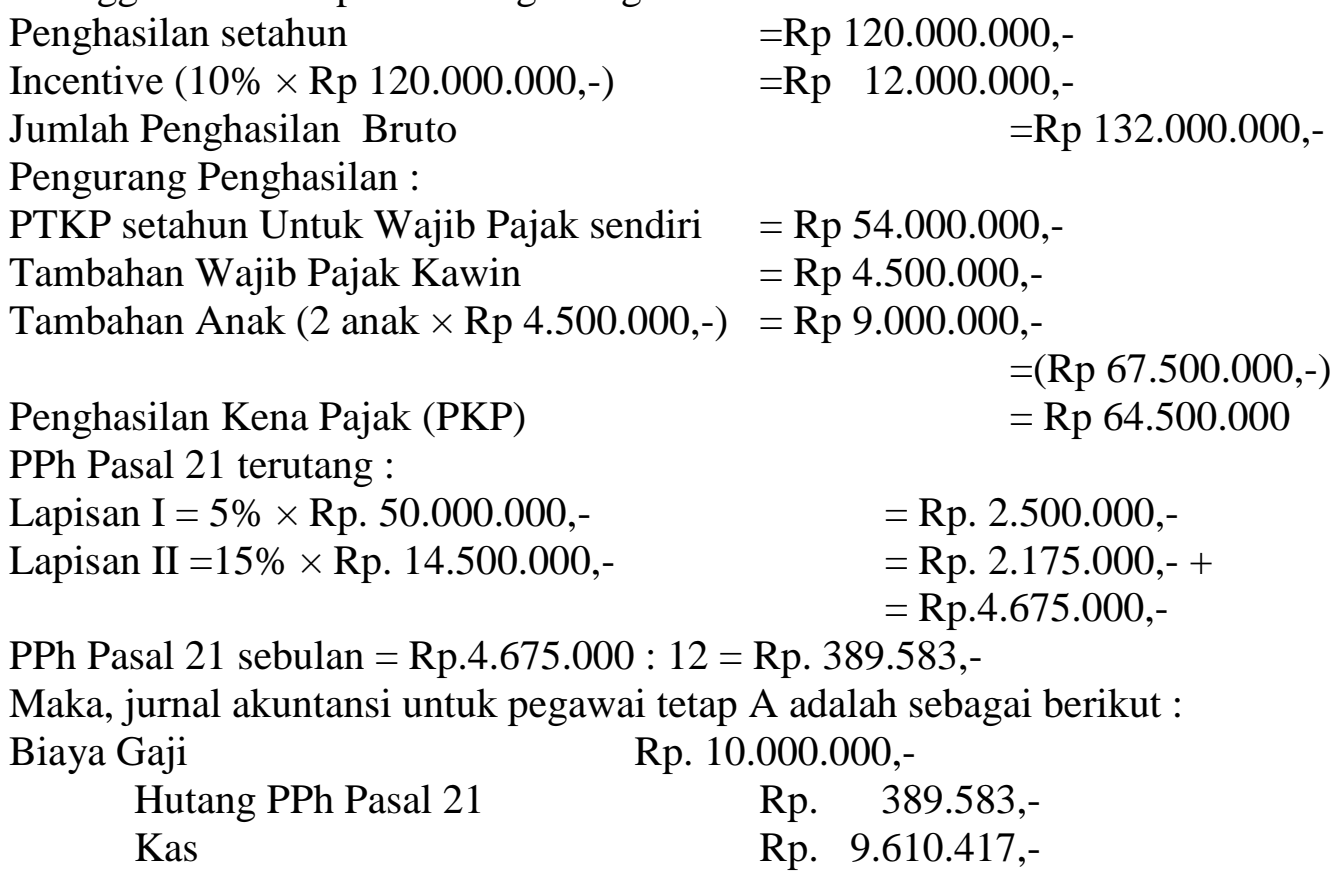

Dan pada saat akan disetorkan ke kas negara, jurnal dicatat sebagai berikut : 


\begin{tabular}{cr}
\hline Hutang PPh Pasal 21 & Rp. 389.583,-- \\
Kas & Rp. 389.583,-
\end{tabular}

\section{KESIMPULAN DAN SARAN}

\subsection{Kesimpulan}

Berdasarkan penerapan ipteks yang telah dilakukan pada PT. Bank Rakyat Indonesia dan pembahasan yang ada, maka kesimpulan yang dapat diambil adalah bahwa Pajak Penghasilan (PPh 21) adalah pajak atas gaji, upah, honorarium, tunjangan dan pembayaran lain yang dalam pemotongan, perhitungan dan pencatatannya harus dilakukan berdasarkan peraturan pajak yang berlaku sebagaimana mestinya.

\subsection{Saran}

Perlunya pengetahuan tentang perpajakan minimal tentang $\mathrm{PPh}$ Pasal 21 agar pegawai dapat mengecek kembali apakah pencatatan dan potongan atas pajak yang tercantum dalam gajinya telah sesuai dengan ketentuan atau tidak.

\section{DAFTAR PUSTAKA}

Mardiasmo. (2011). Perpajakan. Penerbit Andi Jogjakarta.

Pudyatmoko, S. Y. (2009). Pengantar Hukum Pajak. Penerbit Andi, Yogyakarta.

Republik Indonesia. (2015). Peraturan Direktur Jenderal Pajak Nomor PER-32/PJ/2015 tentang Pajak Penghasilan Pasal 21.

Republik Indonesia. (2008). Undang-Undang Nomor 36 tentang Perubahan Keempat atas Undang-Undang Nomor 7 tahun 1983 tentang Pajak Penghasilan.

Republik Indonesia. (1998). Undang-Undang No. 10 tentang perbankan.

Republik Indonesia. (1992). Undang-Undang No. 7 tentang Perbankan.

Republik Indonesia. (1992). Peraturan Pemerintah RI No. 21 tentang Penyesuaian Bentuk Hukum Bank Rakyat Indonesia menjadi Perusahaan Perseroan (Persero)

Republik Indonesia. (1965). Penetapan Presiden No. 17 tentang Pendirian Bank Tunggal milik Negara.

Republik Indonesia. (1960). Peraturan Pemerintah Pengganti Undang-Undang No. 41 tentang Bank Koperasi, Tani dan Nelayan.

Republik Indonesia. (1946). Peraturan Pemerintah No. 1 tentang Bank Rakyat Indonesia.

Tansuria, B. I. (2010). Pajak Penghasilan : Pemotongan dan Pemungutan. Jakarta, Graha Ilmu.

Waluyo. (2017). Perpajakan Indonesia, Edisi 12 Buku I. Jakarta : Salemba Empat. 